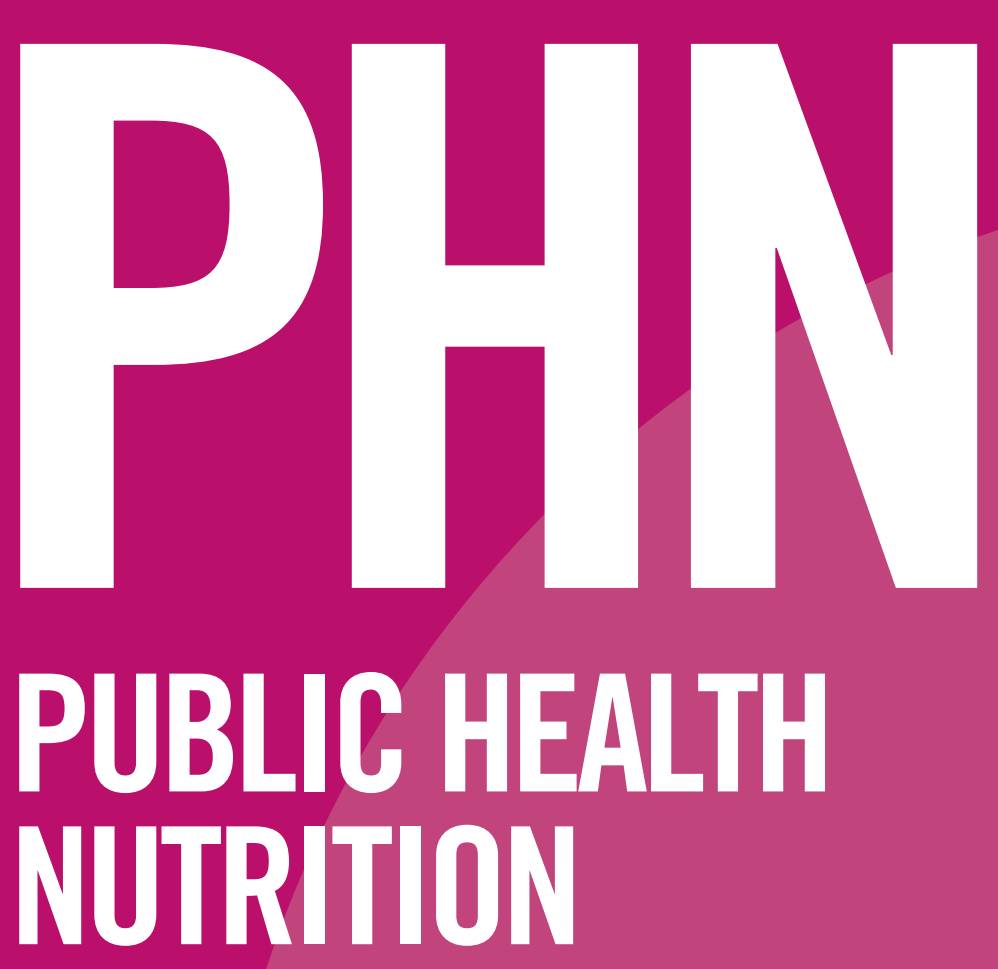

\title{
Volume 21
}

Number 18

December 2018

Available online at
cambridge.org/phn

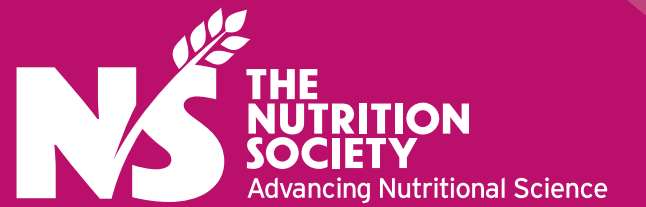




\title{
Public Health Nutrition
}

\author{
Volume 21, 2018 ISSN: 1368-9800 \\ Eighteen issues per year
}

Aims and Scope

\begin{abstract}
Public Health Nutrition provides an international forum for the publication and dissemination of research and scholarship in the form of peer-reviewed original papers and reviews, and for discussion in the form of editorials, commentaries, and correspondence, with a specific focus on nutrition-related public health.

The scope of Public Health Nutrition encompasses nutrition and nutrition policy at a population level, including work on assessment of nutritional status and nutritional environments, communication of nutrition-related information, implementation of programs and interventions, and sustainability of dietary patterns, food systems and supplies. We welcome papers that:

- Address assessment, monitoring, and surveillance of nutritional status or the quality of nutritional environments

- Describe the development and evaluation of methodology for assessment, monitoring, and surveillance in population-based samples

- Identify and analyse behavioural, social, cultural, environmental, economic, and political determinants of nutrition-related public health, and dietary and nutritional factors as determinants of health outcomes
\end{abstract}

- Build intelligence about the development, implementation, and evaluation of interventions and community nutrition programs and efforts

- Describe, discuss, debate and influence nutrition-related public policies

- Serve to build capacity for effective public health nutrition action, including workforce development and educational issues

- Develop perspectives and models to study diet and nutrition as related to the environment and sustainability.

We prefer papers that are innovative and contribute new knowledge to the literature. Papers should be succinct (ie, usually well under 5000 words not including the abstract, references, tables, figures and acknowledgements). Short communications ( $<2000$ words) are welcome. We publish research, scholarship, and discussions that take a population and preventive approach. In addition to original contributions, ideas and suggestions for topics for debate are also welcome. We publish special issues.

Public Health Nutrition is available on the Internet at: journals.cambridge.org/phn

\section{Editor-in-Chief}

Dr. Marilyn Tseng, California Polytechnic State University, USA

\section{Deputy Editors}

Dr Kaleab Baye, Addis Ababa University, Ethiopia

Professor Sandra Capra, University of Queensland, Australia

Professor Hélène Delisle, University of Montreal, Canada

Professor Salome H. Kruger, North-West University, South Africa

Dr Carl Lachat, Gent University, Belgium

Dr Stefanie Vandevijvere, Scientific Institute of Public Health, Belgium

Editors for Systematic Reviews and

Meta-analyses

Professor Dominique Roberfroid, Prince Leopold Institute of Tropical Medicine, Belgium

Dr Amin Salehi-Abargouei, Sahid Sadoughi University of Medical Sciences, Iran

Statistical Editors

Ms Zulfa Abrahams, Human Sciences Research Council, South Africa

Dr Flávia Barbosa, Nutrition Institute, Brazil

Dr Vassiliki Bountziouka, Institute of Child Health, UCL, UK

Mr Fabio Gomes, National Cancer Institute, Brazil

Dr Graham Horgan, Rowett Institute, University of Aberdeen, UK

Dr Eva Maria Navarrete Munoz, CIBER of Epidemiology and Public Health, Spain

Associate Editors

Dr Geeta Appannah, Universiti Putra Malaysia, Malaysia

Dr Kathryn Backholer, Baker IDI Heart and Diabetes Institute, Australia

Dr. Sonia Blaney, Université de Moncton, Canado

Dr Maxine Bonham, Monash University, Australia

Dr Maree Brinkman, Katholieke Universiteit Leuven, Belgium

\section{International Editorial Board}

Dr Mona Calvo, U.S. Food and Drug Administration, USA

Dr Karen Charlton, University of Wollongong, Australia

Dr Colleen Doak, Vrije University, The Netherlands

Dr Shauna Downs, Rutgers School of Public Health, USA

Dr. Isabel Drake, Lund University, Sweden

Dr. Elizabeth Dunford, The George Institute for Global Health, Australia

Professor Mieke Faber, Medical Research Council, South Africa

Professor Ted Greiner, Hanyang University, South Korea

Dr. Muriel Gubert, University of Brasilia, Brazil

Dr Sophie Hieke, European Food Information Council, Belgium

Professor Michelle Holdsworth, University of Sheffield, UK

Dr Alexis Hure, University of Newcastle, Australia

Prof. Stephanie Jilcott Pitts, East Carolina University, USA

Dr Irmgard Jordan, University of Giessen, Germany

Prof. Tilakavati Karupaiah, Taylor's University Malaysia

Dr Bridget Kelly, University of Wollongong Australia

Dr. Gina Kennedy, Bioversity International, Italy

Dr Jessica Kiefte-de Jong, Leiden University College, The Netherlands

Dr Cindy Leung, University of California, USA

Dr Carla Lopes, University of Porto, Portugal

Dr Joreintje Mackenbach, VU University Medical Center, The Netherlands

Dr. Catherine Mah, Dalhousie University, Canada

Professor Alida Melse, Wageningen University, The Netherlands

Asst. Professor Leia Minaker, University of Waterloo, Canada
Asst. Professor Androniki Naska, University of Athens Medical School, Greece

Dr Mary Nicolaou, $A M C$, University of Amsterdam, The Netherlands

Dr Punam Ohri-Vachaspati, Arizona State University, USA

Dr Nasrin Omidvar, Shahid Beheshti University of Medical Sciences, Iran

Professor Nina Overby, University of Agder Norway

Dr Emma Patterson, Centre for Epidemiology and Social Medicine, Sweden

Professor Lisa Pawloski, George Mason University, USA

Ms Catherine Pereira, University of the Western Cape, South Africa

Dr Dora Romaguera-Bosch, Imperial College London, UK

Professor Una MacIntyre, University of Pretoria, South Africa

Dr Koutatsu Maruyama, Ehime University, Japan

Professor Marjanne Senekal, University of Cape Town, South Africa

Dr. YoonJu Song, Catholic University of Korea, South Korea

Dr Anne Marie Thow, University of Sydney Australia

Dr Aida Turrini, Agricultural Research Council, Italy

Dr. Lana Vanderlee, University of Waterloo, Canada

Dr Anniza van de Villiers, South African Medical Research Council, South Africa

Dr Wendy Van Lippevelde, University of Gent, Belgium

Dr Alison Ventura, California Polytechnic State University, USA

Professor Jesus Vioque, Universidad Miguel

Hernandez, Spain

Dr Christina Vogel, University of Southampton, UK

\section{The Nutrition Society}

The society has as its objective the advancement of the scientific study of nutrition and its application to the maintenance of human and animal health.

Particulars of The Nutrition Society and application forms for membership are available from the Honorary Secretary,

The Nutrition Society, 10 Cambridge Court, 210 Shepherds Bush Road, London W6 7NJ, UK.

Telephone +44 (0)20 7602 0228, Fax +44 (0)207602 1756

The Nutrition Society home page is at: http://www.nutritionsociety.org 